\title{
IGUALDAD Y CONCILIACIÓN DE LA VIDA FAMILIAR Y LA ACTIVIDAD PROFESIONAL DE LOS TRABAJADORES Y TRABAJADORAS AUTONOMAS: AVANCES NORMATIVOS Y CUESTIONES PENDIENTES ${ }^{1}$
}

\section{EQUALITY AND RECONCILIATION OF FAMILY LIFE AND AUTONOMOUS ACTIVITY OF AUTONOMOUS WORKERS: NORMATIVE ADVANCEMENTS AND PENDING ISSUES}

\author{
Francisca Ma Ferrando García. Universidad de Murcia - España \\ franferr@um.es
}

\begin{abstract}
Resumen El presente trabajo versa sobre las últimas medidas legislativas introducidas a fin de garantizar los derechos a la maternidad y a la conciliación de la vida familiar y la actividad profesional de las trabajadoras autónomas, desde las perspectivas del principio de igualdad y de la promoción del autoempleo femenino. A tal fin, se estudian las escasas referencias a la conciliación en materia de jornada contenidas en la LETA. Especial atención merecen las bonificaciones en la cotización relacionadas con el ejercicio de sus derechos en materia de maternidad y conciliación, reguladas en los arts. 30, 38 y 38 bis LETA. Asimismo, se trata sobre la posibilidad de contratación de personas asalariadas por los TRADE, introducida en el art. 11.2.a) ET. Finalmente, se analizan las garantías previstas en el art. 15 LETA frente a la facultad de la empresa cliente de resolver el contrato con el TRADE, aspecto este último en el que se observa un claro paralelismo con el régimen aplicable al trabajo por cuenta ajena, a la vez que ciertas carencias que pueden ser consideradas contrarias a la Constitución Española. Todo ello, a la luz de las novedades introducidas por la Ley 6/2017, de Reformas Urgentes del Trabajo Autónomo.
\end{abstract}

Palabras clave Maternidad de la trabajadora autónoma, conciliación de la vida familiar y la actividad profesional, emprendimiento y autoempleo femenino, bonificaciones, extinción de la relación de servicios, TRADE

\footnotetext{
${ }^{1}$ Este estudio se ha efectuado al amparo del Programa de Estancias de Movilidad de profesores e investigadores senior en centros extranjeros ("Salvador de Madariaga"), en el marco del Programa Estatal de Promoción del Talento y su Empleabilidad en I+D+i, Subprograma Estatal de Movilidad, del Plan Estatal de Investigación Científica y Técnica y de Innovación 2013-2016.
} 


\begin{abstract}
This paper studies the various mechanisms that the last legislative reforms have introduced in order to guarantee the right to motherhood and the reconciliation of family life and professional activity of self-employed women, both from the point of view of the principle of equality and from the perspective of the promotion of entrepreneurship and female selfemployment. To this end, the paper reviews the few references to the conciliation in terms of working hours found in the LETA. Special attention deserve the Social Security contribution bonuses applicable to the hiring of employed persons by self-employed women to enable them to exercise their maternity and reconciliation rights, according to arts. 30,38 and 38 bis LETA. Likewise, it deals with the possibility of hiring salaried persons by economically dependent workers, provided by. 11.2.a) ET. Finally, the guarantees introduced in art. 15 LETA as to the faculty of the client to resolve the contract with economically dependent workers, are analyzed, concluding the existence of a clear parallelism with the regime applicable to employment contract, while certain shortcomings that could be considered contrary to the Spanish Constitution. All this, in light of the reforms introduced by Act 6/2017, on Urgent Reforms of Autonomous Work.
\end{abstract}

Key words Self-employed women motherhood, reconciliation of family life and the professional activity, Social Security contribution bonuses, female entrepreneurship, economically dependent workers

\title{
1. Introducción
}

La necesidad de una normativa promocional de la conciliación de la actividad profesional y la vida familiar de los trabajadores y las trabajadoras autónomas, puede fundamentarse tanto en la necesidad de fomentar el autoempleo femenino, como en la idea de hacer efectivos los valores constitucionales de igualdad (arts. 1 y 14 CE) y protección de la familia y de los hijos (art. 39 CE).

En el primer sentido, conviene advertir que la concesión de apoyo económico en la fase inicial del proyecto empresarial, no basta para lograr un entorno jurídico favorable al trabajo autónomo. Por ello, tanto la Estrategia Europa 2020 como la Ley 20/2007, de 11 de julio, del Estatuto del trabajo autónomo (en adelante LETA), recuerdan que es preciso, además, remover los obstáculos al desarrollo de la actividad económica o profesional por cuenta propia [art. 27.2.a) LETA], que normalmente vienen dados por elementos exógenos a la empresa (trabas administrativas y mercantiles, cargas fiscales...) $)^{2}$, pero también pueden consistir en vicisitudes personales que afectan al propio trabajador autónomo e impiden o limitan su dedicación a la actividad. No en vano, de acuerdo con la OCDE, el nivel de conflicto entre la actividad profesional y la familia constituye un indicador, no solo de la salud,

\footnotetext{
${ }^{2}$ Para ello, se han implementado diversas normas, como la Ley 11/2013, de 26 de julio, que desarrolla la Estrategia de Emprendimiento y Empleo Joven 2013-2016, la Ley 14/2013, de 27 de septiembre, de apoyo a los emprendedores y su internacionalización y la Ley 25/2015, de 28 de julio, de mecanismo de segunda oportunidad, reducción de la carga financiera y otras medidas de orden social.
} 
el bienestar y la calidad de vida, sino también de la duración del autoempleo ${ }^{3}$. Por ello, el fomento del trabajo autónomo requiere la articulación de medidas que favorezcan la conciliación y despejen las reservas a emprender una actividad por cuenta propia por temor a no poder compatibilizar los intereses personales y laborales, contribuyendo al mantenimiento de la actividad por parte de las personas con responsabilidades familiares.

No en vano, el colectivo femenino se encuentra manifiestamente subrepresentado en el ámbito del trabajo autónomo, como evidencia el hecho de que las mujeres constituyan un tercio de los trabajadores por cuenta propia, tanto en Europa ${ }^{4}$ como en España ${ }^{5}$. De ahí que, como recuerda la Comunicación de 2 de julio de 2008, titulada "Agenda social renovada: oportunidades, acceso y solidaridad en la Europa del siglo $X X I$ ", sea necesario "actuar contra las diferencias de género relacionadas con la actividad empresarial y conciliar mejor la vida privada con la vida profesional" ${ }^{6}$. Más recientemente, la Comunicación de la Comisión Relanzar el espíritu emprendedor en Europa $^{7}$, ha insistido en la necesidad de buscar fórmulas que faciliten la conciliación de la actividad empresarial y familiar. También en el ámbito nacional, el art. 27.3 LETA establece que la elaboración de la política de fomento del trabajo autónomo, debe tender "al logro de la efectividad de la igualdad de oportunidades entre mujeres y hombres", igualdad a la que lógicamente contribuye la posibilidad de conciliación entre la actividad empresarial o profesional y la vida familiar.

3 OECD (2011). Doing better for families. Chapter 1: Families are changing. http://www.oecd.org/els/soc/47701118.pdf. Cit. por Annink, A., Den Dulk, L. y Steijn, B. (2016). WorkFamily conflict among employees and the self-employed across Europe. Social Indicators Research. Vol. 126. p. 572. Disponible en https://link.springer.com/article/10.1007/s11205-015-0899-4

4 Según el informe "Female entrepreneurs", de la Comisión Europea (disponible en https://ec.europa.eu/growth/smes/promoting-entrepreneurship/we-work-for/women_en), las mujeres constituyen el $52 \%$ del total de la poblacion europea, pero solamente el 34,4\% de quienes trabajan por cuenta propia y el $30 \%$ de las personas emprendedoras. Señala el citado informe que, entre los principales retos a los que tienen que hacer frente las mujeres emprendedoras, se halla la conciliación de su negocio con las responsabilidades familiares. Para un análisis de los datos estadisticos sobre emprendimiento femenino en la UE, véase, asímismo, el informe "Statistical Data on Women Entrepreneurs in Europe" (disponible en http://ec.europa.eu/DocsRoom/documents/7481/attachments/1/translations).

${ }^{5}$ En España, de las 1.976.125 personas físicas inscritas como trabajadoras por cuenta propia en los diferentes regímenes por cuenta propia de la Seguridad Social, los varones representan el 65,2 \% y las mujeres el 34,8\% del total (datos tomados del Informe elaborado por la Subdirección General del Trabajo Autónomo del Ministerio de Empleo y Seguridad Social, correspondiente al tercer trimestre de 2017, disponible en http://www.empleo.gob.es/es/sec_trabajo/autonomos/economiasoc/autonomos/estadistica/2017/3trim/PUBLICACION__RESUMEN_DE_RESULTADOS_SEPTIEMBRE_ 2017.pdf).

${ }^{6}$ Citada por la Directiva 2010/41/UE, de 7 de julio, sobre la aplicación del principio de igualdad de trato entre hombres y mujeres que ejercen una actividad autónoma, y por la que se deroga la Directiva $86 / 613 / C E E$, de 11 de diciembre.

${ }^{7}$ Bruselas, 9 enero $2013 \operatorname{COM}(2012) 795$ final.

IQUAL. REVISTA DE GÉNERO E IGUALDAD, 2018, 1,32-61 
Ahora bien, la efectividad del derecho del trabajador autónomo a la conciliación de su actividad profesional con la vida personal y familiar, consagrado en el art. 4.3.g) LETA $^{8}$, tiene como presupuesto el reconocimiento de otros derechos accesorios de cuya extensión y garantías depende la virtualidad del primero, y que se hallan relacionados con la jornada laboral y los descansos de quienes trabajan por cuenta propia, con la facultad de suspender total o parcialmente su actividad en las situaciones de maternidad, paternidad, riesgo durante el embarazo, riesgo durante la lactancia y adopción o acogimiento, que el propio precepto reconoce, y con la posibilidad de continuar su actividad mediante la contratación de una persona que le sustituya, cuando la cesación de la actividad resulte inconveniente o demasiado gravosa.

A todo ello hay que añadir, sin duda, la necesidad de una protección social suficiente durante las situaciones de suspensión de la actividad por motivos de maternidad y paternidad, etc., mediante las oportunas prestaciones de Seguridad Social, si bien, por motivos de espacio, se ha optado por ceñir este estudio al análisis de las previsiones normativas que, en aplicación de las precitadas directrices, introducen mecanismos de conciliación con relación al trabajo autónomo, y que se traducen en determinados beneficios en las cotizaciones a la Seguridad Social de los trabajadores autónomos en las situaciones anteriormente referidas, a los que se suman las escasas referencias a la jornada de trabajo de los trabajadores autónomos económicamente dependientes (TRADE) y a la facultad de interrupción de su actividad por motivos justificados, la posibilidad de que los autónomos dependientes contraten a trabajadores sustitutos por cuenta ajena por motivos de conciliación, así como en la interdicción, en tal caso, de la extinción del contrato por parte de la empresa cliente.

\section{Beneficios en la cotización a la Seguridad Social en materia de maternidad y conciliación}

La menor participación de las mujeres en la actividad por cuenta propia, ha dado lugar a numerosas recomendaciones europeas en favor de la orientación de las

\footnotetext{
${ }^{8}$ Aunque también cabe citar como fundamento de este derecho, el art. 44 de la Ley Orgánica 3/2007, de 22 de marzo, para la igualdad efectiva de mujeres y hombres, en cuanto reconoce el derecho de conciliación a los trabajadores y las trabajadoras, en general, sin limitarlo a quienes trabajan por cuenta ajena. En este sentido, Barrios Baudor, G.L. (2011). La conciliación de la vida personal, familiar y profesional de los trabajadores autónomos: estado de la cuestión y propuestas de reforma. Estudios financieros. Revista de trabajo y seguridad social: Comentarios, casos prácticos: recursos humanos. num. 345. p. 51-96; Morgado Panadero, P. Hacia un derecho de ciudadanía sin límites para el trabajador autónomo: el reconocimiento de su vida personal, familiar y profesional. En Morgado Panadero, P. (Coord.). (2011). Trabajo autónomo e igualdad: reflexiones desde el Derecho del Trabajo. Cizur Menor, España: Aranzadi. p. 57.
} 
políticas de fomento del empleo hacia el colectivo femenino ${ }^{9}$, justificando sobradamente su consideración como objetivo prioritario de las medidas de promoción del autoempleo y creación de empresas, según los arts. $2 . d)^{10}$ y $30^{11}$ de la Ley de Empleo, al que, por ello, deben destinarse programas específicos de actuación.

Pese a ello, siguiendo el ejemplo de otros países europeos, como Francia ${ }^{12}$ y el Reino Unido ${ }^{13}$, el legislador español ha sido muy parco a la hora de introducir incentivos directos al autoempleo femenino. Entre las escasas medidas adoptadas en este sentido, cabe citar la Orden TAS/1622/2007, de 5 de junio, que regula la concesión de subvenciones para la promoción del empleo autónomo, en cuanto considera a las

${ }^{9}$ En este sentido, la Comunicación de la Comisión al Parlamento Europeo, al Consejo, al Comité Económico y Social Europeo y al Comité de las Regiones, Hacia una recuperación generadora de empleo, de 18 de abril de 2012, expresa la necesidad de promover y apoyar el trabajo por cuenta propia, las empresas sociales y las empresas de nueva creación, encomiando a este fin los sistemas de conversión de las prestaciones de desempleo en subvenciones para la creación de empresas, orientados a "los grupos con mayor potencial (como los trabajadores desempleados con capacidades profesionales, las mujeres o los jóvenes)".

${ }^{10}$ El art. 2.d) Ley de Empleo (Texto Refundido aprobado por Real Decreto Legislativo 3/2015, de 23 de octubre), cita entre los objetivos generales de la política de empleo, "(a)segurar políticas adecuadas de integración laboral dirigidas a aquellos colectivos que presenten mayores dificultades de inserción laboral, especialmente jóvenes, mujeres, discapacitados y parados de larga duración mayores de 45 años".

${ }^{11}$ Expresamente, identifica como colectivos prioritarios "las personas con especiales dificultades de integración en el mercado de trabajo, especialmente jóvenes, con particular atención a aquellos con déficit de formación, mujeres, parados de larga duración, mayores de 45 años, personas con responsabilidades familiares, personas con discapacidad o en situación de exclusión social, e inmigrantes".

${ }^{12}$ En el país galo no se prevén beneficios específicos en la cotización de la mujer autónoma, pues la ayuda a la creación de empresas (aide aux demandeurs d'emploi créant ou reprenant une entreprise, ACCRE) se conceden sin distinción de sexo. Dicha ayuda, regulada en el art. L. 161-1-1 Code de la Sécurité sociale, consiste en una exención parcial durante doce meses (ampliable por 24 meses más, para los emprendedores acogidos al régimen fiscal de micro-empresas), en la cotización a la Seguridad Social respecto de los ingresos que no sobrepasen el $120 \%$ del SMIC en vigor (21.119 $€$ en 2016), se halla destinada a diversos colectivos enunciados en el art. L. 5141-1 Code du Travail (demandantes de empleo beneficiarios de prestaciones de desempleo o de determinadas ayudas sociales, o a los jóvenes hasta determinada edad en función de que tengan reconocida o no una situación de discapacidad, entre otros) en cualquier caso sin distinción del sexo, siempre que no sobrepasen las cifras de negocio del régimen fiscal correspondiente a las micro-empresas. Las medidas específicas en materia de emprendimiento femenino consisten en ayudas financieras (Fonds du garantie á l'initiative des femmes, FGIF) y en la creación de redes de acogida y apoyo a la mujer emprendedora.

${ }^{13}$ En lo que concierne al Reino Unido, se observa igualmente la ausencia de beneficios en la cotización para las autónomas y emprendedoras, desde la supresión en 1977 del régimen de cotización reducida para las mujeres casadas que trabajaran, tanto por cuenta ajena como por cuenta propia (Section 53 Social Security Contributions and Benefits Act 1992). Hasta abril de 1977, las trabajadoras autónomas casadas podían optar por un régimen de cotización reducida al National Insurance (llamado comúnmente, "small stamp"), equivalente al 5.85\% de los ingresos semanales, en lugar de la tarifa correspondiente a las cotizaciones del Class 2 que corresponde a los trabajadores autónomos en general. Sin perjuicio de su carácter discriminatorio por razón el estatus familiar o civil, este régimen de cotización reducida comportaba peores prestaciones de Seguridad Social e, incluso, la imposibilidad de acceder a alguna de ellas (salvo que se tratara de viudas, madres de hijos menores de 12 años o tuvieran a su cargo a personas enfermas o discapacitadas). 
mujeres desempleadas y, en su caso, discapacitadas, entre los colectivos susceptibles de percibir una subvención de mayor cuantía [art. 3.1.a)].

En lo que concierne a los beneficios en la cotización a la Seguridad Social, las referencias específicas a la trabajadora autónoma se resumen en el establecimiento de un límite de edad más generoso para el acceso a los incentivos previstos para jóvenes emprendedores (que se eleva de 30 a 35 años, si se trata de mujeres, según el art. 31.2 (LETA) ${ }^{14}$, y a la previsión de bonificaciones para las víctimas de violencia de género que decidan iniciar una actividad por cuenta propia (art. 32 LETA) ${ }^{15}$.

Mayor impacto en el colectivo femenino, pueden tener los incentivos a la cotización de los familiares colaboradores de trabajadores autónomos (art. 35 LETA) y de los familiares del titular de la explotación agraria incluidos en el Régimen Especial de la Seguridad Social de los Trabajadores por Cuenta Propia o Autónomos (RETA) a través del Sistema Especial para Trabajadores por Cuenta Propia Agrarios (art. 37 LETA), pues aunque esta medida se prevé sin distinción para trabajadores familiares de ambos sexos, quien figura como titular del negocio o explotación en ciertos

\footnotetext{
${ }^{14}$ Tras la reforma introducida por la Ley 6/2017, de 24 de octubre, de Reformas Urgentes del Trabajo Autónomo, y en el caso de que causen alta inicial o no hubiera estado de alta en los 2 años anteriores, los trabajadores por cuenta propia menores de 30 años, o de 35 años si se trata de mujeres, podrán aplicarse, además de las reducciones y bonificaciones previstas en el art. 31.1 LETA para quienes superen dicha edad, una bonificación adicional equivalente al $30 \%$, sobre la cuota por contingencias comunes, en los 12 meses siguientes a la finalización del periodo de bonificación previsto en el apartado $1^{\circ}$, siendo la cuota a reducir el resultado de aplicar a la base mínima de cotización que corresponda el tipo mínimo de cotización vigente en cada momento, incluida la incapacidad temporal. En consecuencia, para los y las jóvenes que emprendan una actividad por cuenta propia la duración máxima de las reducciones y bonificaciones será de 36 meses. Nótese que la Ley 6/2017 ha supuesto una ampliación de la tarifa plana de 50 euros, prevista en el art. 31.1 LETA, de 6 meses a un año, y la reducción del plazo para reemprender con derecho a la bonificación prevista en el mismo precepto, de 5 años a 2 años.

${ }^{15}$ La 31/2015 extendió los incentivos previstos para las personas con discapacidad a las víctimas de violencia de género y víctimas del terrorismo que causen alta inicial en el RETA (o en el grupo primer del RETM) o que no hubieran estado de alta en el período, que tras la Ley 6/2017 se reduce de los 5 a los 2 años inmediatamente anteriores. Así pues, en virtud del art. 32 LETA, los beneficios en la cotización de las trabajadoras víctimas de violencia de género alcanzan un período de cinco años, que se estructura en dos etapas:
}

a) Una primera, que comprende los 12 meses inmediatamente siguientes a la fecha de efectos del alta, en la que los trabajadores podrán beneficiarse, alternativamente, en función de que coticen o no por la base mínima que les corresponda, de una cuota por contingencias comunes, incluida la incapacidad temporal, reducida a la cuantía de 50 euros mensuales o de una reducción en dicha cuota equivalente al $80 \%$ del resultado de aplicar a la base mínima de cotización que corresponda el tipo mínimo de cotización vigente.

b) Con posterioridad al período inicial de 12 meses, y con independencia de la base de cotización elegida, estos autónomos podrán aplicarse una bonificación sobre la cuota por contingencias comunes, siendo la cuota a bonificar el $50 \%$ del resultado de aplicar a la base mínima de cotización que corresponda el tipo mínimo de cotización vigente en cada momento, incluida la incapacidad temporal, por un período máximo de hasta 48 meses, hasta completar un periodo máximo de 5 años desde la fecha de efectos del alta.

Por otra parte, la Ley 6/2017 ha introducido la posibilidad de volver a disfrutar de esta bonificación en caso de reemprender tras un periodo de tres años de baja en el RETA (art. 32.2 LETA). 
sectores de actividad (especialmente el agrario) es tradicionalmente el hombre. Por esta razón, la reducción de costes puede incentivar el alta de las cónyuges colaboradoras $^{16}$, contribuyendo a visibilizar el trabajo femenino $y$, sobre todo, permitiendo que estas trabajadoras accedan a las prestaciones contributivas de Seguridad Social.

Otro tanto cabe decir de los incentivos destinados a quienes tienen especiales responsabilidades familiares, ya que si bien se destinan indiferenciadamente a personas de uno $u$ otro sexo, es sabido que estas cargas son, aun en la actualidad, asumidas en mayor medida por las mujeres, por lo que suponen un serio obstáculo al desarrollo de su actividad profesional ${ }^{17}$, siendo esta la razón por la que las políticas de conciliación son consustanciales a las de igualdad efectiva entre hombres y mujeres. Por ello, conviene realizar un análisis más detenido de las bonificaciones en las cuotas de Seguridad Social previstas en los arts. 30,38 y 38 bis LETA.

\subsection{Bonificación a la contratación por cuenta ajena para sustituir a trabajadores y trabajadoras autónomas que tienen a su cargo hijos o familiares dependientes o con discapacidad}

Siguiendo el orden del articulado de la LETA, la primera de las bonificaciones que contempla dicha norma con el fin de facilitar la conciliación entra la actividad profesional y la vida familiar, aparece en el art. $30^{18}$. El citado precepto establece una bonificación en las cuotas a la Seguridad Social para las personas incluidas en el RETA y en el grupo primero del RETM ${ }^{19}$, en los siguientes supuestos: a) por cuidado de menores a su cargo, hasta la edad máxima que la Ley 9/2017 ha elevado de 7 a 12 años; b) por tener a su cargo a un familiar, por consanguinidad o afinidad hasta el segundo grado inclusive, en situación de dependencia debidamente acreditada; o c) por tener a su cargo a un familiar con parálisis cerebral, enfermedad mental o discapacidad intelectual con un grado de discapacidad reconocido igual o superior al

\footnotetext{
${ }^{16}$ El número de colaboradores familiares en alta en la Seguridad Social asciende a 199.885, de los cuales 90.185 son $\quad$ varones $\quad y \quad 109.700 \quad$ mujeres (http://www.empleo.gob.es/es/sec_trabajo/autonomos/economiasoc/autonomos/estadistica/2017/3trim/PUBLICACION_RESUMEN_DE_RESULTADOS_SEPTIEMBRE_ 2017.pdf).

${ }^{17}$ Selma Penalva, A. (2016). Incentivos a la mujer emprendedora. Especial referencia a las recientes reformas introducidas por la Ley 31/2015 de fomento del trabajo autónomo y de la Economía Social. RTSS-CEF. núm. 394, pp. 75 y 76.

${ }^{18}$ Dicho precepto recoge los beneficios en la cotización de los trabajadores autónomos previstos en su día por el art. 9 del Real Decreto-ley 1/2015, de 27 de febrero, de mecanismo de segunda oportunidad, reducción de carga financiera y otras medidas de orden social.

${ }^{19}$ El art. 30.8 LETA (introducido por el art. 5. Tres de la Ley 6/2017, de 24 de octubre, de Reformas Urgentes del Trabajo Autónomo), extiende las bonificaciones "a los trabajadores por cuenta propia que queden incluidos en el grupo primero de cotización del Régimen Especial de la Seguridad Social de los Trabajadores del Mar", siempre que cumplan los requisitos establecidos en el art. 30 LETA.
} 
$33 \%$ o una discapacidad física o sensorial con un grado de discapacidad reconocido igual o superior al $65 \%$, cuando dicha discapacidad esté debidamente acreditada y siempre que dicho familiar no desempeñe una actividad retribuida ${ }^{20}$.

La bonificación asciende al $100 \%$ de la cuota de autónomos por contingencias comunes, resultante de aplicar a la base media que tuviera el trabajador o trabajadora en los doce meses anteriores a la fecha en que se acoja a esta medida, el tipo mínimo de cotización vigente en cada momento en el RETA. Ahora bien, cuando el período de alta en el RETA sea inferior a doce meses, la base media de cotización se calculará desde la fecha del alta (art. 30.1 LETA).

El beneficio en la cotización tendrá una duración máxima de doce meses, previendo el art. 30.3 LETA que en el caso de que el menor causante de la bonificación alcance la edad máxima de 12 años con anterioridad a la finalización del período de 12 meses, podrá mantenerse la bonificación hasta alcanzar el período máximo de 12 meses previsto, siempre que se cumplan el resto de condiciones.

El derecho a la bonificación prevista en el art. 30 LETA se sujeta a tres condiciones:

1) En primer lugar, la permanencia en alta en el RETA durante el período de bonificación y hasta los seis meses siguientes al vencimiento del plazo de disfrute de la misma (art. 30.3 LETA) ${ }^{21}$. De esta forma, se fuerza el mantenimiento de la actividad profesional durante las vicisitudes familiares que afectan a la persona beneficiaria de la bonificación a las que alude la norma.

2) En segundo término, se exige la contratación en interinidad conforme al art. 15.1.c) ET (art. 30.7 LETA), de un trabajador o trabajadora ocupada en la actividad profesional que da lugar al alta en el Sistema de Seguridad Social del trabajador autónomo, que deberá mantenerse durante todo el período de su disfrute, y por un tiempo no inferior a tres meses desde la fecha de inicio del disfrute de la bonificación (art. 30.2 LETA) ${ }^{22}$. Conviene advertir que el contrato de interinidad puede concertarse

\footnotetext{
${ }^{20}$ Aunque, como se ha señalado anteriormente, en el Reino Unido no se han previsto bonificaciones en la cotización específicamente destinadas a las trabajadoras autónomas, se establecen algunos beneficios en la cotización para las personas con cargas familiares que hayan podido suponer una interrupción en su carrera de cotización. La ayuda, denominada "Carer's Credit", consiste precisamente en la obtención de un crédito del National Insurance a fin de completar las lagunas de cotización generadas como consecuencia de la atención y cuidado durante al menos 20 horas a la semana, de una o más personas con determinado grado de discapacidad o dependencia (Section $23 \mathrm{~A}$ de la Social Security Contributions and Benefits Act 1992. Recuperada de http://www.legislation.gov.uk/ukpga/1992/4/pdfs/ukpga_19920004_300617_en.pdf).

${ }^{21}$ Pues, en caso contrario, el trabajador autónomo deberá reintegrar (en su totalidad) el importe de la bonificación disfrutada (art. 30.3 in fine LETA).

${ }^{22}$ Sin embargo, el art. 30.2 LETA precisa que "cuando se extinga la relación laboral, incluso durante el periodo inicial de 3 meses, el trabajador autónomo podrá beneficiarse de la bonificación si contrata a otro trabajador por cuenta ajena en el plazo máximo de 30 días". En caso de incumplimiento de mantenimiento de la relación laboral durante, al menos, 3 meses desde la fecha de inicio del disfrute de la bonificación, el autónomo deberá reintegrar el importe de la bonificación disfrutada, salvo que proceda a contratar a otro trabajador por cuenta ajena en el plazo de 30 días (art. 30.3 LETA). No obstante lo anterior, la obligación de reintegro no se aplica cuando "la extinción esté motivada por
} 
tanto a tiempo completo como a tiempo parcial, por una jornada no inferior al $50 \%$ de la aplicable a un trabajador a tiempo completo, supuesto este último en el que la bonificación será del 50 por ciento ${ }^{23}$, parece que con independencia de que la jornada del trabajador interino sea superior a dicho porcentaje respecto de la jornada ordinaria, lo que puede inclinar al autónomo a la contratación por una jornada no superior al $50 \%$ de la aplicable a tiempo completo.

En este punto, conviene tener en cuenta que la Disposición Adicional $14^{\mathrm{a}} \mathrm{ET}$ no contempla la aplicación a estos supuestos de los beneficios previstos respecto de los contratos de interinidad que se celebren con beneficiarios de prestaciones por desempleo (de nivel contributivo o asistencial), que lleven más de un año como perceptores, para cubrir el puesto de trabajo del trabajador en excedencia para atender al cuidado de un hijo o familiar conforme al art. 46.3 ET. En consecuencia, el autónomo o autónoma no podrá disfrutar de la reducción del $95 \%$ en las cotizaciones empresariales a la Seguridad Social por contingencias comunes que dicha disposición establece durante el primer año del contrato de interinidad.

3) En tercer y último lugar, el art. 30.4 LETA exige expresamente como condición de acceso a la bonificación, que el autónomo carezca de trabajadores asalariados en la fecha de inicio de la aplicación de la bonificación y durante los doce meses anteriores a la misma ${ }^{24}$. Quizá esta medida pretenda limitar la bonificación a los autónomos que no dispongan de trabajadores en plantilla susceptibles de sustituirles. Con todo, esta precaución parte de una presunción que no tiene porqué corresponderse con la realidad, pues puede darse el caso de pequeños empresarios que, aun contando con trabajadores por cuenta ajena en plantilla, no puedan recurrir a ellos para atender la actividad que venía realizando el trabajador autónomo de forma personal, ya sea por razones cuantitativas o cualitativas, circunstancia que bien podría haber justificado la contratación bonificada, aun teniendo más trabajadores en plantilla, toda vez de que

causas objetivas o por despido disciplinario cuando una u otro sea declarado o reconocido como procedente, ni en los supuestos de extinción causada por dimisión, muerte, jubilación o incapacidad permanente total, absoluta o gran invalidez del trabajador o por resolución durante el periodo de prueba". La inclusión entre las causas liberatorias de la extinción durante el período de prueba resulta excesiva, toda vez que durante dicho período no se exige justificación de la decisión extintiva.

${ }^{23}$ Para, Selma Penalva, A. (2016). Incentivos a la mujer emprendedora. Especial referencia a las recientes reformas introducidas por la Ley 31/2015 de fomento del trabajo autónomo y de la Economía Social. cit., p. 82, la contratación a tiempo parcial presupone la realización de la actividad autónoma a tiempo parcial. No obstante la norma no lo exige expresamente, ni se ha desarrollado reglamentariamente hasta la fecha la cotización a tiempo parcial prevista en el art. 25 LETA (aunque la Disp. Adic. $5^{a}$ de la Ley 6/2017, encarga la determinación de los elementos necesarios para su implantación a la Subcomisión para el estudio de la reforma del RETA, constituida en el Congreso de los Diputados), por lo que, sin perjuicio de que así sea de facto, lo cierto es que el trabajador o trabajadora autónoma permanecerá de alta en el RETA a tiempo completo, beneficiándose únicamente del 50 por ciento de la bonificación.

${ }^{24}$ Si bien no computan a estos efectos los interinos contratados al amparo del RD-Ley 11/1998, de 4 de septiembre, para la sustitución del trabajador autónomo durante los periodos de descanso por maternidad, paternidad, adopción o acogimiento tanto preadoptivo como permanente o simple, riesgo durante el embarazo o riesgo durante la lactancia natural (art. 30.4 LETA). 
se exige que la persona contratada interinamente sea ocupada en la actividad profesional que da lugar al alta en el Sistema de Seguridad Social del trabajador autónomo (art. 30.2 LETA).

\subsection{Bonificación de cuotas de Seguridad Social para trabajadoras y trabajadores autónomos durante el descanso por maternidad, paternidad, adopción, guarda con fines de adopción, acogimiento, riesgo durante el embarazo o riesgo durante la lactancia natural}

El art. 38 LETA establece la bonificación de cuotas de Seguridad Social para las personas en alta en el RETA o en el grupo primero de cotización del Régimen Especial de la Seguridad Social de los Trabajadores del Mar (RETM), durante el descanso por maternidad ${ }^{25}$, paternidad, adopción, guarda con fines de adopción ${ }^{26}$, acogimiento, riesgo durante el embarazo o riesgo durante la lactancia natural. Dicha bonificación se cifra en el 100 por cien de la cuota de autónomos, que resulte de aplicar a la base media que tuviera el trabajador o la trabajadora en los doce meses anteriores a la fecha en la que se acoja a esta medida, el tipo de cotización establecido como obligatorio para trabajadores incluidos en el régimen especial de Seguridad Social que corresponda por razón de su actividad por cuenta propia. No obstante, en el caso el periodo de alta en los precitados regímenes especiales fuera inferior a 12 meses de alta, la base media de cotización se calculará desde la fecha de alta.

En su versión original, introducida por la Ley 31/2015, esta bonificación venía condicionada a la contratación de una persona desempleada mediante contrato de interinidad bonificado, celebrado al amparo del RD-Ley 11/1998, de 4 de septiembre. Es más, la bonificación se hallaba limitada al período durante el que coincidieran el contrato de interinidad del sustituto o sustituta y la suspensión de actividad por dichas causas con el límite máximo del período de suspensión ${ }^{27}$.

\footnotetext{
${ }^{25}$ En Italia, en caso de maternidad de la trabajadora autónoma (durante el primer año edad del niño) o de adopción o acogimiento (durante el primer año desde la recepción del niño), se aplica la bonificación (de un $50 \%$ ) en la cotización del trabajador o trabajadora por cuenta ajena que, en su caso, contrate la empresa cliente, para asumir temporalmente (por un período máximo de doce meses) el trabajo encomendado a la autónoma siempre que la empresa cuente con menos de 20 empleados en plantilla (art. 4.5 del Decreto Legislativo 26 marzo 2001, n. 151, que aprueba el Testo unico delle disposizioni legislative in materia di tutela e sostegno della maternità e della paternità, a norma dell'articolo 15 della Legge 8 marzo 2000, n. 53).

${ }^{26}$ La referencia a la guarda con fines de adopción ha sido incluida por el art. 6 de la Ley 6/2017.

27 Igualmente, el art. 11 de la Ley 5/2011, de 29 de marzo, de Economía Social, extendió las bonificaciones a los socios trabajadores o socios de trabajo de las sociedades cooperativas, si bien en tal caso la cuantía de la bonificación se halla en función del régimen de Seguridad Social en el que se encuadre el socio, de manera que: a) Cuando se halle incluido en un régimen de Seguridad Social para trabajadores por cuenta ajena, tendrá derecho a una bonificación del $100 \%$ en las cuotas empresariales de la Seguridad Social, por contingencias comunes y profesionales, incluidas las aportaciones empresariales de las cuotas de recaudación conjunta. b) Cuando esté encuadrado en un régimen de la
} 
Pues bien, tras la reforma introducida por la Ley 6/2017, desaparece la exigencia de contratar a un trabajador o trabajadora en interinidad, lo que resulta coherente con la normativa aplicable según la cual el disfrute de estos permisos por el trabajador o la trabajadora autónoma, es posible sin la contratación de una persona para sustituirlos, pues lo que la normativa vigente exige a la beneficiaria de la prestación (salvo que este encuadrada en el Sistema especial de trabajadores por cuenta propia agrarios o se trate de una TRADE), es presentar ante la Entidad Gestora una declaración de situación de actividad, sobre la persona que gestione directamente el establecimiento mercantil, industrial o de otra naturaleza del que sea titular o, en su caso, el cese temporal o definitivo en la actividad desarrollada ${ }^{28}$.

La generalización de la bonificación a todas las personas que hayan ejercido su derecho al descanso en las situaciones anteriormente referidas es esencial para garantizar el ejercicio de estos derechos pues, hasta la fecha, salvo que la beneficiaria procediera a concertar un contrato de interinidad, tenía que seguir cotizando a la Seguridad Social durante la baja (art. 13.2 del Reglamento General de Cotización ${ }^{29}$ ), siendo el incumplimiento de la obligación de cotizar causa de suspensión de la prestación (art. 47 LGSS).

En otro orden de consideraciones, es preciso advertir que, como consecuencia de esta reforma, el régimen de bonificación previsto para los supuestos de descanso previstos en este apartado se separa del establecido respecto de los derechos de conciliación previstos en el art. 30 LETA, en cuyo caso se mantiene la exigencia de contratación a un trabajador o trabajadora interina para sustituir a la trabajadora autónoma.

Por último, la bonificación prevista en el art. 38 LETA es compatible con la contemplada en el RD-Ley 11/1998, cuyo art. 1.d) extiende a los trabajadores autónomos y socios trabajadores o de trabajo de las sociedades cooperativas el derecho a disfrutar de una bonificación del $100 \%$ en las cuotas empresariales de la Seguridad Social, incluidas las de accidentes de trabajo y enfermedades profesionales, y en las aportaciones empresariales de las cuotas de recaudación conjunta, correspondientes a los contratos de interinidad suscritos para sustituirles durante las situaciones anteriormente referidas.

Seguridad Social propio de trabajadores autónomos, la cuantía se calcula en la forma prevista por el art. 38.1 LETA.

${ }^{28}$ Cfr. Resolución de 4 de febrero de 2004, del Instituto Nacional de la Seguridad Social, sobre cumplimiento por los trabajadores por cuenta propia de la obligación establecida en el párrafo segundo del artículo 12 del Real Decreto 1273/2003, de 10 de octubre, sobre cobertura de las contingencias profesionales de los trabajadores por cuenta propia o autónomos y ampliación de la prestación por incapacidad temporal para los trabajadores por cuenta propia.

${ }^{29}$ Real Decreto 2064/1995, de 22 de diciembre, por el que se aprueba el Reglamento General sobre Cotización y Liquidación de otros Derechos de la Seguridad Social. 


\subsection{Reincorporación de las trabajadoras autónomas tras el cese motivado por maternidad y otras responsabilidades familiares}

Una de las principales novedades introducidas por la Ley 6/2017 en esta materia, consiste en la bonificación de la cuota por contingencias comunes de las trabajadoras autónomas incluidas en el RETA o en el grupo primero de cotización del RETM, en el supuesto en que, tras cesar su actividad por maternidad, adopción, guarda con fines de adopción, acogimiento y tutela, en los términos legalmente establecidos, vuelvan a realizar una actividad por cuenta propia en los dos años siguientes a la fecha del cese. En virtud de dicha bonificación, contemplada en el nuevo art. 38 bis LETA, la cuota de las trabajadoras autónomas "quedará fijada en la cuantía de 50 euros mensuales durante los 12 meses inmediatamente siguientes a la fecha de su reincorporación al trabajo, siempre que opten por cotizar por la base mínima establecida con carácter general en el régimen especial que corresponda por razón de la actividad por cuenta propia", o bien, en el caso de que "optasen por una base de cotización superior a la mínima indicada en el párrafo anterior, podrán aplicarse durante el período antes indicado una bonificación del 80 por ciento sobre la cuota por contingencias comunes, siendo la cuota a bonificar la resultante de aplicar a la base mínima de cotización establecida con carácter general en el correspondiente régimen especial el tipo mínimo de cotización vigente en cada momento, incluida la incapacidad temporal".

La medida viene a resucitar la bonificación prevista por la Disp. Adic. $65^{\mathrm{a}}$ Ley 30/2005, de 29 de diciembre, de PGE para 2006, para las trabajadoras autónomas que se reincorporaran después de la maternidad, suprimidas por el Real Decreto-Ley 20/2012, de 13 de julio.

La reforma plantea la excepcional situación de otorgar un trato más beneficioso a las trabajadoras autónomas respecto de las contratadas por cuenta ajena, a quienes no se ha restituido la bonificación destinada a incentivar la contratación indefinida a tiempo completo de las mujeres en el plazo de 24 meses desde la fecha del parto, adopción o acogimiento, o tras 5 años de inactividad laboral, siempre que anteriormente hubieran estado de alta en un régimen de Seguridad Social un mínimo de 3 años, contemplada originariamente por el art. 2.1 de la Ley 43/2006, de 29 de diciembre, para la mejora del crecimiento y del empleo. Tras su supresión por Ley 35/2010, de 17 de septiembre, la contratación de trabajadoras en estas circunstancias quedaba sin especial incentivo ${ }^{30}$.

\footnotetext{
$3^{30}$ Toda vez que la normativa vigente se limita a mejorar las bonificaciones especiales a la contratación de mujeres en sectores en los se hallen subrepresentadas (la Orden de 16 de septiembre de 1998 (art. Único) considera que las mujeres están subrepresentadas en todas las profesiones de la Clasificación Nacional de ocupaciones excepto las que figuran en el Anexo a dicha Orden), y a condición de que se encuentren en la franja de edad priorizada. Para un estudio critico de esta situación, véase Ferrando García, F.M., García Romero, M.B. y López Aniorte, M.C. Reflexiones sobre la aplicación en España de la estrategia europea de empleo. En Cabeza Pereiro, J. y Fernández Prol, F. (Coords.). (2013). Políticas de Empleo (pp. 409-427). Cizur Menor, España: Aranzadi.
} 


\section{La consecución de una jornada compatible con la vida familiar: una asignatura pendiente}

A menudo, la actividad por cuenta propia se desarrolla mediante largas jornadas de trabajo que, en sectores como la hostelería o el pequeño comercio, pueden superar con creces la jornada máxima aplicable a los trabajadores por cuenta ajena ${ }^{31}$. El impacto negativo de esta realidad en la vida familiar y personal de los autónomos es innegable ${ }^{32}$, por lo que parece lógico plantear la conveniencia y necesidad de que el legislador intervenga en este ámbito.

El principal obstáculo a la intervención legal viene dado por la propia naturaleza del trabajo autónomo, ya que, por definición, el trabajador o la trabajadora autónoma organizan libremente su actividad profesional ${ }^{33}$. No obstante, ello no impide que surjan conflictos entre las exigencias derivadas de su actividad profesional y la atención de las responsabilidades familiares ${ }^{34}$, antes bien, la necesidad de adaptarse a los intereses y demandas de los clientes condiciona su jornada de trabajo, planteándose la paradoja de que quienes, en teoría, gozan de mayor autonomía y capacidad de autogestionar su actividad, realizan jornadas de trabajo más prolongadas que entran en conflicto con su vida familiar.

En cualquier caso, la acción normativa en esta materia se encuentra amparada en razones tan poderosas como la protección de la familia y los hijos, la necesidad de fomentar la incorporación de la mujer al mercado de trabajo, tanto por cuenta ajena como por cuenta propia, la seguridad y salud en el trabajo y la prevención de riesgos laborales. Se trata de valores, principios y objetivos dignos de una atención, cuanto

\footnotetext{
$3^{31}$ Sobre la cuestión, véase Barrios Baudor, G.L. (2011). La conciliación de la vida personal, familiar y profesional de los trabajadores autónomos: estado de la cuestión y propuestas de reforma. cit. p. 58 y la documentación allí citada.
}

${ }^{32}$ Así ocurre, especialmente en las fases iniciales del emprendimiento, según exponen Tremblay, D.-G., Chevrier C. y Di Loreto, M. (2007). Self-Employment: A better reconciliation of personal and professional life ... or more crossover in social times?. Research Note of the Bell Canada Research Chair on Technology and Work Organization, Télé-université, UQAM. Núm. 07. p. 12. Recuperado de https://www.teluq.uquebec.ca/chairebell/pdf/NR_CB_2007_07.pdf

${ }^{33}$ La ausencia de dependencia respecto de un empresario es la razón por la que un sector doctrinal mantiene la imposibilidad de aplicar a los autónomos los parámetros previstos por el ET en materia de conciliación en lo que concierne a la interrupción, suspensión y extinción del contrato. En este sentido, véase Moreno De Vega y Lomo, F. (2008). El trabajador autónomo: la conciliación entre la actividad profesional y su vida familiar. Revista de Derecho Social. núm. 43. p. 94.

\footnotetext{
${ }^{34}$ Así se constata, entre otros estudios, en Annink, A., Den Dulk, L. y Steijn, B. (2016). Work-Family conflict among employees and the self-employed across Europe. cit. p. 580; Pérez Agulla, S. y Gil Plana, J. (2015). Los trabajadores autónomos y la conciliación de la vida familiar, personal y profesional. En Mella Méndez. L. (Dir.). Conciliación de la vida laboral y familiar y crisis económica. Estudios desde el Derecho Internacional y Comparado. España: Editorial DELTA. p. 87. Sobre la percepción que las emprendedoras tienen de las largas jornadas y su impacto negativo en el emprendimiento, véase Ortiz Garcia, P. y Olaz Capitán, A. (2016). Elements that contribute to boost female entrepreneurship: A prospective analysis. Suma de Negocios. Volume 7. Issue 15. p. 58 . Recuperado de https://papers.ssrn.com/sol3/papers.cfm?abstract_id=3013282.
} 
menos, similar a las consideraciones de organización del consumo que vienen justificando el establecimiento de horarios comerciales por parte de las autoridades públicas ${ }^{35}$.

Con todo, lo cierto es que el estudio del articulado de la LETA arroja un resultado muy pobre en este punto. Las previsiones que el art. 14 de esta norma contiene en materia de jornada son parcas y su ámbito de aplicación alcanza exclusivamente a los TRADE, respecto de quienes se reconoce el derecho a una interrupción de su jornada anual de 18 días hábiles (art. 14.1 LETA) ${ }^{36}$ y delega al contrato individual o a los acuerdos de interés profesional la determinación del régimen de descanso semanal, festivos y la cuantía máxima de la jornada de actividad (art. 14.2 LETA). En consecuencia, en defecto de tales acuerdos, la cuestión queda en manos del "contrato individual", supeditado al interés del cliente y al juego de la competencia.

La única referencia específica en materia de conciliación se contiene en el apartado 4 de este precepto, a cuyo tenor "(e)l horario de actividad procurara adaptarse a los efectos de poder conciliar vida personal, familiar y profesional" (art. 14.4 LETA). El carácter admonitivo del precepto ("procurara") está muy lejos de garantizar de forma efectiva el derecho a la conciliación por medio de una jornada razonable, a lo sumo, recoge una expectativa de derecho ${ }^{37}$, cuya materialización dependerá de lo pactado en el contrato individual o el acuerdo de interés profesional. Ciertamente, el art. 34.8 del $\mathrm{ET}^{3^{8}}$ tampoco constituye un paradigma del legislador preocupado por la conciliación de la vida laboral y familiar de los trabajadores y trabajadoras por cuenta ajena, pero, en su caso, la negociación colectiva provee una regulación más concreta y protectora que la que, hasta la fecha, los acuerdos de interés profesional, negociados conforme al art. 13 LETA, contienen respecto de los TRADE.

Por su parte, el art. 16 LETA regula, también para los TRADE, las interrupciones justificadas de la actividad profesional por diversas causas, entre los que se cuentan "la necesidad de atender responsabilidades familiares urgentes, sobrevenidas $e$ imprevisibles" [art. 16.b) LETA], "la maternidad, paternidad, adopción o acogimiento"

\footnotetext{
${ }^{35}$ Rodríguez Egío, M.M. (2016). Hacia un trabajo autonómo decente. Albacete, España: Bomarzo, p. 178.

${ }^{36}$ Frente a los 30 días naturales que el art. 38.1 del Real Decreto Legislativo 2/2015, de 23 de octubre, por el que se aprueba el texto refundido de la Ley del Estatuto de los Trabajadores (en adelante ET), reconoce a los trabajadores y las trabajadoras por cuenta ajena.

37 Barrios Baudor, G.L. (2011). La conciliación de la vida personal, familiar y profesional de los trabajadores autónomos: estado de la cuestión y propuestas de reforma. cit. p. 73.

$3^{8}$ Según el cual: "El trabajador tendrá derecho a adaptar la duración y distribución de la jornada de trabajo para hacer efectivo su derecho a la conciliación de la vida personal, familiar y laboral en los términos que se establezcan en la negociación colectiva o en el acuerdo a que llegue con el empresario respetando, en su caso, lo previsto en aquella.
}

A tal fin, se promoverá la utilización de la jornada continuada, el horario flexible u otros modos de organización del tiempo de trabajo y de los descansos que permitan la mayor compatibilidad entre el derecho a la conciliación de la vida personal, familiar y laboral de los trabajadores y la mejora de la productividad en las empresas." 
[art. 16.d) LETA], y el "riesgo durante el embarazo y riesgo durante la lactancia natural de un menor de 9 meses" [art. 16.e) LETA]. No obstante, por razones de carácter sistemático, el alcance de esta facultad y las garantías de su ejercicio frente a acciones de clientes posiblemente perjudicados, se analizan en otro apartado de este estudio.

En consecuencia, las escasas referencias a la conciliación limitan su aplicación a los trabajadores económicamente dependientes, quienes formalmente representan una mínima proporción de las personas dadas de alta en regímenes especiales para trabajadores por cuenta propia ${ }^{39}$. Únicamente el art. 4.3.g) LETA da cobertura a los autónomos con carácter general, de forma que todas las personas que desarrollan una actividad por cuenta propia deberían tener derecho a la conciliación de su actividad profesional con la vida personal y familiar, y más concretamente, "el derecho a suspender su actividad en las situaciones de maternidad, paternidad, riesgo durante el embarazo, riesgo durante la lactancia y adopción o acogimiento, tanto preadoptivo como permanente o simple, de conformidad con el Código Civil o las leyes civiles de las Comunidades Autónomas que lo regulen, siempre que su duración no sea inferior a un año, aunque éstos sean provisionales, en los términos previstos en la legislación de la Seguridad Social". Según esta configuración legal, el derecho a la conciliación del autónomo común se reduce a la suspensión de la actividad ligada exclusivamente a las prestaciones de Seguridad Social en las referidas circunstancias, quedando sin cobertura otras figuras como la adaptación de la jornada o la suspensión por motivos distintos de los expresados, como el cuidado de hijo, de familiar o de persona con discapacidad a cargo, salvo que así se pacte en el contrato entre el autónomo y el cliente.

Cabe advertir el importante papel que, en este punto, puede tener la introducción de cláusulas sociales en la contratación pública. En efecto, el art. 145.1 de la Ley de Contratos del Sector Público ${ }^{40}$ (LCSP), establece que la adjudicación de los contratos se realizará utilizando una pluralidad de criterios de adjudicación en base a la mejor relación calidad-precio, que se "evaluará con arreglo a criterios económicos y cualitativos", entre los que el órgano de contratación podrán incluir aspectos medioambientales o sociales, vinculados al objeto del contrato, entre los que el apartado 2 del mismo precepto cita "los planes de igualdad de género que se apliquen en la ejecución del contrato $y$, en general, la igualdad entre mujeres y hombres; el fomento de la contratación femenina; la conciliación de la vida laboral, personal y familiar".

\footnotetext{
${ }^{39} \mathrm{El} 30$ de septiembre de 2017, el número de TRADE ascendía a 10.099, según los datos registrados por la Subdirección General del Trabajo Autónomo, del Ministerio de Empleo y Seguridad Social (http://www.empleo.gob.es/es/sec_trabajo/autonomos/economia-soc/autonomos/estadistica/).

$4^{0}$ Ley 9/2017, de 8 de noviembre, de Contratos del Sector Público, por la que se transponen al ordenamiento jurídico español las Directivas del Parlamento Europeo y del Consejo 2014/23/UE y 2014/24/UE, de 26 de febrero de 2014 .
} 
Por su parte, el art. 202.2 LCSP, establece la posibilidad de incluir en el pliego de cláusulas administrativas determinadas consideraciones de tipo social o relativas al empleo, entre las que cita, las destinadas a "eliminar las desigualdades entre el hombre y la mujer en dicho mercado, favoreciendo la aplicación de medidas que fomenten la igualdad entre mujeres y hombres en el trabajo; favorecer la mayor participación de la mujer en el mercado laboral y la conciliación del trabajo y la vida familiar". Pues bien, el apartado 4 del mismo precepto, añade con buen criterio que "todas las condiciones especiales de ejecución que formen parte del contrato serán exigidas igualmente a todos los subcontratistas que participen de la ejecución del mismo", de forma que, de incluirse en la licitación condiciones especiales de ejecución relacionadas con la conciliación, las mismas deberían aplicarse a los autónomos y autónomas que formen parte de la cadena de subcontratación.

\section{La contratación de personas por cuenta ajena para contribuir a la conciliación de la actividad profesional y la vida familiar de los TRADE}

La noción de trabajo autónomo económicamente dependiente, contenida en el art. 11.1 LETA, incluye entre sus elementos constitutivos el carácter personal de la prestación de servicios, requisito que comporta la necesidad de que el autónomo desarrolle la actividad económica por sí mismo y, según el apartado 2.a) del mismo precepto, sin contar con trabajadores por cuenta ajena a su cargo. Como ha advertido la doctrina, de este requisito se deduce "la insustituibilidad de la persona del autónomo dependiente, circunstancia que le hará mantener grandes puntos de identidad con el trabajador por cuenta ajena" ${ }^{\prime 41}$.

No obstante, como excepción a este principio, la Ley 31/2015 incorporó en el art. 11.2.a) LETA la posibilidad de que los TRADE contraten, bajo la modalidad del art. 15.1.c) ET, a un único trabajador por cuenta ajena en los supuestos de riesgo durante el embarazo y la lactancia natural de un menor de nueve meses, durante los períodos de descanso por maternidad, paternidad, adopción o acogimiento (preadoptivo o permanente), o por reducción de la actividad para el cuidado de menores de siete años ${ }^{42}$ o de un familiar a su cargo hasta el segundo grado inclusive en situación de dependencia o con una discapacidad igual o superior al 33 por ciento debidamente acreditada.

En los supuestos de cuidado de menor de siete años o persona en situación de dependencia o discapacidad a cargo del trabajador autónomo, el contrato se celebrará

\footnotetext{
${ }^{41}$ Galiana Moreno, J.M. y Selma Penalva, A. (2009). El trabajo autónomo dependiente dos años después de la aprobación del Estatuto del trabajo autónomo. Aportaciones prácticas del RD 197/2009 que desarrolla la Ley 20/2007. Revista del Ministerio de Trabajo e Inmigración. núm. 83. p. 294.

$4^{2}$ Como puede apreciarse, la Ley 6/2017 ha olvidado o no ha querido extender la medida de elevar la edad de 7 a 12 años de los menores a cargo que causa el derecho a una bonificación en las cuotas a la Seguridad Social, a los efectos de autorizar la contratación de un trabajador por cuenta ajena.
} 
por una jornada equivalente a la reducción de la actividad efectuada por el trabajador autónomo sin que pueda superar el 75 por ciento de la jornada de un trabajador a tiempo completo comparable, en cómputo anual. En estos supuestos, la duración del contrato estará vinculada al mantenimiento de la situación de cuidado de la persona a cargo, con una duración máxima, en todo caso, de doce meses.

Según se ha expuesto, el art. 11.2.a) LETA solamente permite la contratación de un único trabajador por cuenta ajena aunque concurran dos o más de los supuestos previstos. Sin embargo, y de forma excepcional, el trabajador autónomo podrá contratar a un trabajador para sustituir al inicialmente contratado sin que, en ningún momento, ambos trabajadores por cuenta ajena puedan prestar sus servicios de manera simultánea ni la duración conjunta de ambos contratos pueda superar el periodo máximo de duración de la contratación previsto en los supuestos de suspensión del contrato de trabajo por incapacidad temporal, maternidad, paternidad, adopción o acogimiento, riesgo durante el embarazo o lactancia natural o protección de la mujer víctima de violencia de género [art. 11.2.a) LETA].

Ahora bien, finalizada la causa que dio lugar a dicha contratación, el trabajador autónomo podrá celebrar un nuevo contrato con un trabajador por cuenta ajena por cualquiera de las causas previstas anteriormente, siempre que, en todo caso, entre el final de un contrato y la nueva contratación transcurra un periodo mínimo de doce meses, salvo que el nuevo contrato tuviera como causa la baja por riesgo durante el embarazo o la lactancia natural o el descanso por maternidad, paternidad, adopción o acogimiento.

La posibilidad de que el autónomo económicamente dependiente tenga a trabajadores asalariados a su cargo, suscitó ciertas reservas recogidas en el Dictamen del CES 7/2015, de 13 de mayo, sobre el Anteproyecto de Ley que dio lugar a la Ley 31/2015. El referido documento objetaba que dicha medida desvirtuaría la naturaleza de esta figura, pues podía "plantear problemas de indefinición de aspectos de la relación de trabajo del asalariado contratado". Ahora bien, el requisito de desarrollo de la actividad a título personal por parte del autónomo económicamente dependiente no siempre aparece vinculado a la exigencia de no contratación de trabajadores asalariados en los ordenamientos de nuestro entorno. Así, mientras en Alemania la noción de persona asimilada a trabajador por cuenta ajena (arbeitnehmeränliche Person), implica la imposibilidad de contratar a trabajadores por cuenta ajena ${ }^{43}$, en otros países se admite tal posibilidad, bien con carácter general, v.gr. en Países Bajos, bien puntualmente, como es el caso de Italia. En este último país, el art. 14.2 de la Legge 22 maggio de 2017, num. 81, permite que, en caso de maternidad, la autónoma pueda ser sustituida por otro trabajador autónomo, previo

\footnotetext{
43 Perulli, A. (2003). Travail économiquement dépendant/parasubordination: les aspects juridiques, sociales et économiques. $\quad$ p. $66 . \quad$ Recuperado de http://www.metiseurope.eu/content/pdf/n8/7_parasubordination.pdf 
consentimiento del contratista durante el periodo de suspensión de su actividad ${ }^{44}$, además de la ya comentada posibilidad, prevista en el art. 4.5 D. Lgs. 151/2001, de que la empresa cliente contrate temporalmente a trabajadores por cuenta ajena para sustituir a la trabajadora autónoma. No obstante, aun cuando se admita la contratación por parte del autónomo dependiente, normalmente se parte del presupuesto de que actuará en el marco de una microempresa ${ }^{45}$.

Así mismo, el Dictamen cuestionaba "el recurso a modalidades contractuales de trabajo por cuenta ajena que no están concebidas para estos casos, como es el contrato de interinidad". El documento no hacía sino constatar un hito más en el devenir de este contrato, cuyo originario objeto legal era la sustitución de los trabajadores con derecho a reserva del puesto de trabajo [art. 15.1.c) ET], si bien con el paso del tiempo se ha admitido su utilización para cubrir temporalmente un puesto de trabajo durante el proceso de selección o promoción para su cobertura definitiva e, incluso, para la sustitución de los trabajadores autónomos [art. 1.d) RD-Ley 11/1998] ${ }^{46}$, primando de esta forma la causa de la sustitución sobre la naturaleza de la actividad del sustituido ${ }^{47}$.

Frente a estas objeciones, la Exposición de Motivos de la propia Ley 31/2015 argumentaba que esta medida contribuiría a resaltar la capacidad auto-organizativa del TRADE, "dando un paso más en su diferenciación respecto al trabajador por cuenta ajena, eliminando así los posibles espacios de difícil delimitación entre ambas categorías", pues no cabe olvidar que el carácter personal e infungible de su prestación es una de las características que comparte con los trabajadores por cuenta ajena.

Por otra parte, como ha advertido la doctrina, la posibilidad de contratación de trabajadores por cuenta ajena en estos casos, permite al autónomo mantener su actividad bajo el estatus especial del TRADE, más protector que el previsto para los

\footnotetext{
${ }^{44}$ No superior a 150 días. La citada ley viene a reponer la protección que en su día contemplara el art. 66 del Decreto Legislativo 10 septtembre 2003, n. 276 (derogado por el art. 52 del Decreto Legislativo 15 giugno 2015, n. 81), respecto de las titulares de un contrato de colaboración coordinada y continuativa a proyecto (trabajo parasubordinado), si bien la norma original preveía el derecho a la suspensión por un periodo máximo de 180 días [véase, Rausei, P. (2017). Lavoro autonomo e agile. IPSOA Guide Operative. Milanofiori Assago, Italia: Wolters Kluwer. p. 109]

45 Antonmattei, P.H. y Sciberras, J.C. (2008). Le travailleur économiquement dépendant: quelle protection?. Rapport à M. le Ministre du Travail, des Relations sociales, de la Famille et de la Solidarité. Droit Social, núm. 2, p. 11. Recuperado de http://travail-emploi.gouv.fr/IMG/pdf/Rapport-AntonmatteiSciberras-07NOVo8.pdf.

${ }^{46}$ En virtud del art. 18 de la Ley 39/1999, de 5 de noviembre, para promover la conciliación de la vida familiar y laboral de las personas trabajadoras.

47 Tampoco se ha resuelto el problema que la contratación plantea con relación a la afiliación del TRADE a un sindicato, ya que, como se sabe, la misma es posible siempre y cuando el autónomo no tenga trabajadores asalariados a su cargo (art. 3.1 LOLS).
} 
trabajadores autónomos en general ${ }^{48}$. Es más, como se analizará posteriormente, la sustitución del autónomo dependiente impedirá, aunque no en todos los casos previstos en el art. 11.2.a), que el cliente proceda a la extinción del contrato alegando que la interrupción de la actividad le ha ocasionado "un perjuicio importante que paralice o perturbe el normal desarrollo de su actividad", conforme a lo previsto en el art. 16.3 LETA.

Conviene, por último, tener presente que el contrato de interinidad concertado para sustituir al TRADE en los supuestos autorizados por el art. 11.2.a) LETA, es compatible con la bonificación por conciliación de la vida profesional y familiar que justifica dicha contratación, prevista en el art. 30 de la propia norma, a la que se ha hecho referencia líneas arriba.

\section{Interrupción de la actividad por causas vinculadas a la maternidad y las responsabilidades familiares y protección frente a la extinción del contrato que vincula al TRADE y a la empresa cliente}

Como se ha señalado anteriormente, el art. 16.1 LETA contiene un listado de supuestos en los que la interrupción de la actividad se considera justificada y, por consiguiente, según lo previsto en el art. 16.3 de la misma norma, no amparan la extinción del contrato "por voluntad del cliente por causa justificada" a los efectos del art. 15.1.f) LETA. En consecuencia, si la empresa cliente procede a la resolución contractual en estos casos, el autónomo dependiente podrá exigir una indemnización por los daños y perjuicios que la decisión extintiva ocasione, conforme al art. 15.3 LETA.

Junto a las causas justificadas de interrupción de la actividad por parte del autónomo dependiente vinculados a la conciliación ya contempladas en la LETA desde su redacción original (maternidad y paternidad), la Ley 31/2015 incorporó los supuestos de adopción o acogimiento [art. 16.1.d) LETA] y riesgo durante el embarazo y la lactancia natural de un menor de 9 meses [art. 16.1.e) LETA] ${ }^{49}$. En estos casos la conservación del negocio jurídico merced a la figura de la interrupción justificada del contrato permite, de forma análoga a lo que ocurre con la suspensión en la relación

\footnotetext{
$4^{8}$ Selma Penalva, A. (2016). Incentivos a la mujer emprendedora. Especial referencia a las recientes reformas introducidas por la Ley 31/2015 de fomento del trabajo autónomo y de la Economía Social. cit., p. 77.

${ }^{49}$ Con carácter previo a la reforma, un sector doctrinal [Fotinopoulou Basurko, O. (2010). Algunos aspectos relativos a la prevención y protección de la maternidad y la lactancia de las trabajadoras autónomas y TRADES. Lan Harremanak: Revista de relaciones laborales. núm. 23, p. 266; Navarro Nieto, F. (2012). Especialidades del régimen profesional del TRADE en jornada, interrupciones y extinción de la relación contractual. Temas Laborales. núm. 114. p. 47], había entendido que pese a la no inclusión expresa del riesgo durante el embarazo y la lactancia en el art. 16.1, debían considerarse incluidas en dicho precepto, toda vez que el art. 4.2.g) LETA, contempla como derecho individual de los trabajadores autónomos el derecho a suspender su actividad en los casos de riesgo durante el embarazo o la lactancia.
} 
laboral, una redistribución de los riesgos de la esfera del trabajador al empresario cliente, en aras de garantizar determinados valores y derechos fundamentales ${ }^{50}$.

Sin embargo, no se incluye expresamente en este elenco de causas justificadas de interrupción de la actividad que protegen al trabajador frente a la extinción contractual, los supuestos de cuidado de menores de 7 años o de un familiar a cargo, a los que sí alude el art. 11.2.a) cuando autoriza la contratación de interinos por tal causa. Tampoco parece que estos supuestos sean subsumibles en la letra b) del art. 16.1 LETA, relativa a "(l)a necesidad de atender responsabilidades familiares urgentes, sobrevenidas e imprevisibles", fundamentalmente por la exigencia de que sean "imprevisibles". La imprecisión del precepto, ha llevado a un sector doctrinal a defender una remisión analógica a las causas previstas en el art. 37.3.b) $E T^{51}$, por considerar que el art. 16.1.b) LETA se refiere a circunstancias de duración muy limitada en el tiempo ${ }^{52}$. No obstante, del tenor literal del art. 16.1.b) LETA no se deduce tal condición ${ }^{53}$, ni todos los supuestos que recoge el art. 37.3.b) ET pueden considerarse "imprevisibles" ${ }^{54}$, pues tal cualidad requiere un desconocimiento previo de la circunstancia aludida ${ }^{55}$. La concreción del citado apartado es, pues, una tarea necesaria a fin de evitar conflictos interpretativos, y en tanto no se produzca una reforma del precepto, corresponderá hacerla al contrato o al acuerdo de interés profesional.

Ahora bien, y pese a que el párrafo $1^{\circ}$ del art. 16.3 LETA impide al cliente ejercer la facultad resolutoria que le confiere el art. 15.1.f) LETA en los precitados supuestos de interrupción justificada del contrato, el párrafo $2^{\circ}$ del mismo precepto le permite resolver el contrato suscrito con el trabajador autónomo, cuando la interrupción de la

\footnotetext{
${ }^{50}$ De Heredia Ruiz, I.B. (2008). La extinción del contrato del autónomo dependiente. Análisis (crítico) de su regulación jurídica (y propuestas de reforma). Aranzadi Social. núm. 4. BIB 2008|859, p. 16, se refiere a "la salvaguarda de la institución familiar, la promoción de una determinada política demográfica, la protección del trabajo femenino en general y la promoción de la entrada y permanencia de la mujer en el mercado de trabajo".

${ }^{51}$ En este sentido, véase Navarro Nieto, F. (2012). Especialidades del régimen profesional del TRADE en jornada, interrupciones y extinción de la relación contractual. cit. p. 46.

$5^{2}$ Agut García, C. y Núñez González, C. (2012). The Regulation of Economically Dependent Selfemployed Work in Spain: A Critical Analysis and a Comparison with Italy. E-Journal of International and Comparative Labour Studies, Vol.1, Núm. 1-2, p. 129. Recuperado de http://ejcls.adapt.it/index.php/ejcls_adapt/article/view/22/68

${ }^{53}$ De Heredia Ruiz, I.B. (2008). La extinción del contrato del autónomo dependiente. Análisis (crítico) de su regulación jurídica (y propuestas de reforma). Aranzadi Social. núm. 4. BIB 2008|859, cit., p. 17.

54 Conviene recordar que el art. 37.3.b) ET alude a las interrupciones del contrato de trabajo por nacimiento de hijo y por el fallecimiento, accidente o enfermedad graves, hospitalización o intervención quirúrgica sin hospitalización que precise reposo domiciliario, de parientes hasta el segundo grado de consanguinidad o afinidad.

55 Barrios Baudor, G.L. (2011). La conciliación de la vida personal, familiar y profesional de los trabajadores autónomos: estado de la cuestión y propuestas de reforma. cit. p. 75.
} 
actividad "ocasione un perjuicio importante al cliente que paralice o perturbe el normal desarrollo de su actividad"156.

Con razón, este último inciso ha sido criticado por la doctrina más autorizada, por entender que dicha cláusula vacía de contenido la garantía frente a la resolución previamente establecida, ya que cualquier interrupción de la actividad puede perturbar el "normal desarrollo" de la actividad de la empresa cliente ${ }^{57}$, posibilitando la extinción del contrato sin que se genere derecho a indemnización a favor del trabajador autónomo.

Por otra parte, esta facultad del cliente entra en clara contradicción con los derechos del autónomo a la conciliación [art. 4.3.g) LETA] y a su integridad física, así como a una protección adecuada de su seguridad y salud en el trabajo ${ }^{58}$ (en lo que concierne a los supuestos de riesgo durante el embarazo y la lactancia), según lo previsto en el art. 4.3.e) de la misma norma. Tampoco parece compatible con la prohibición de discriminación del trabajador autónomo ${ }^{59}$, tanto por razón de sexo [art. 4 Directiva 2010/41/UE y art. 4.3.a) LETA], en la medida en que las circunstancias conectadas con la maternidad se hallan íntimamente relacionadas con el sexo ${ }^{60}$, como

\footnotetext{
${ }^{56}$ En análogo sentido, el art. 14.1 de la Legge n. 81/2017 antes citada, establece que el embarazo de la trabajadora autónoma que presta su actividad de forma continuada para un comitente, no comporta la extinción de la relación de trabajo, cuya ejecución, a solicitud de la trabajadora, quedará en suspenso, sin derecho a contraprestación, por un periodo no superior a 150 días por año natural, "sin perjuicio del interés del cliente" ("fatto salvo il venir meno dell'interesse del committente"). Según la doctrina judicial italiana recaída al amparo del precedente art. 66 D. Lgs. 276/2003, dicha expresión significa que, la suspensión del contrato comporta la extensión de su duración, por un período no superior al máximo indicado, siempre que se mantenga el interés de ambas partes en la continuación del proyecto y / o el programa, y en la medida en que la obra o servicio pueda ser realizada con posterioridad a la fecha inicialmente pactada, pues, de lo contrario, la prórroga puede no tener ningún efectividad [Tribunal de Milán, en sentencia de 11 de febrero de 2013, juez Lualdi, en Lavoro nella giurisprudenza. (2013). Vol. 6. p. 621, cit. en Oreste Cagnasso, O. y Vallebona A. (2014). Dell'impresa e del lavoro, artt. 2188-2246. En Gabrielli, E. (Dir.). Commentario del Codice Civile. Volumen 4. Nota 804. Italia: Utet Giuridica; y en Contratto a progetto. Rivista telematica di diritto del lavoro. Recuperado de http://www.dielle.it/giurisprudenza/30-contratto-a-progetto/215-in-genere].
}

57 En este sentido, véanse, Lopez Aniorte, M.C. y Rodriguez Egio, M.M. (2015). ¿Favorece el emprendimiento femenino el vigente régimen jurídico de la protección por maternidad biológica?. Revista de derecho social. No 70. p. 102. Fernández-Costales Muñiz, J. y Álvarez Cuesta, H. (2009). Régimen profesional, derechos colectivos y Seguridad Social del trabajador autónomo tras la Ley 20/2007, de 11 de julio, del Estatuto del Trabajo Autónomo. León, Madrid: Eolas. p. 83.

${ }^{58}$ Fotinopoulou Basurko, O. (2010). Algunos aspectos relativos a la prevención y protección de la maternidad y la lactancia de las trabajadoras autónomas y TRADES. Lan Harremanak: Revista de relaciones laborales. núm. 23, cit., p. 267.

59 Luque Parra, M., Martínez Fons, D. (2007). Régimen profesional del trabajador autónomo económicamente dependiente. En Del Rey Guanter, S. (dir.). Comentarios al estatuto del trabajo autónomo. Valladolid, España: Lex nova. p. 197.

${ }^{60}$ Montoya Melgar, A. (2009). El contrato del TRADE. Madrid, España: Civitas. p. 158. Lopez Aniorte, M.C. y Rodriguez Egio, M.M. (2015). ¿Favorece el emprendimiento femenino el vigente régimen jurídico de la protección por maternidad biológica?. cit. p. 102. En este sentido, el art. 8 LO 3/2007, establece que todo trato desfavorable a las mujeres, relacionado con el embarazo o la maternidad, constituye discriminación directa por razón de sexo. 
por motivos parentales o familiares, pues aunque dicha causa de discriminación no está contemplada expresamente en el precitado art. 4.3.a) LETA, es subsumible en la cláusula abierta que alude, reproduciendo el tenor del art. ${ }_{14} \mathrm{CE}$, a "cualquier otra condición o circunstancia personal o social".

En este punto, es oportuno traer a colación la STC 26/2011, de 14 de marzo, que, aunque relativa a los trabajadores por cuenta ajena, parece perfectamente extrapolable a los autónomos, en cuanto afirma "la dimensión constitucional de las medidas normativas tendentes a facilitar la conciliación de la vida familiar y laboral de las personas trabajadoras, tanto desde la perspectiva del derecho a la no discriminación por razón de las circunstancias personales (art. $14 \mathrm{CE}$ ), como desde la perspectiva del mandato de protección a la familia y a la infancia (art. 39 CE)", y señala la necesidad de que dicha dimensión prevalezca y sirva "de orientación para la solución de cualquier duda interpretativa que pueda suscitarse ante la aplicación a un supuesto concreto de una disposición que afecte a la conciliación profesional y familiar".

Por ello, aunque solamente haya supuesto una solución parcial a la paradoja planteada, fue bienvenida la modificación efectuada por la Ley 31/2015 en el art. 16.3 in fine LETA, con el fin de excluir expresamente la facultad resolutoria del cliente en los casos de descanso por maternidad, paternidad, adopción o acogimiento y riesgo durante el embarazo y la lactancia natural, en los que el autónomo dependiente mantenga la actividad mediante la contratación de un trabajador interino en virtud de la posibilidad que le otorga el art. 11.2.a) LETA. Esta medida contribuye a garantizar el mantenimiento de la relación entre el trabajador y la empresa cliente, evitando el cese de este trabajador por cuenta propia por estos motivos de conciliación. En efecto, autorizando esta sustitución, se pretende evitar que la interrupción de la actividad por el TRADE por causas vinculadas a la conciliación de su actividad profesional con su vida familiar, que podría ocasionar la resolución del contrato con su cliente ${ }^{61}$. De esta manera -argumenta la Exposición de Motivos de la precitada norma-, "se viene a subsanar la falta de protección existente respecto a aspectos relativos a la conciliación de la vida profesional y personal de este colectivo de profesionales".

Sorprende, en todo caso, que la garantía frente a la facultad del cliente de resolver el contrato ex art. 15.1.f) LETA, no alcance a los supuestos de cuidado de menor o persona dependiente o discapacitada a su cargo. Quizá se deba esta omisión al hecho de que en estos supuestos no se produce una interrupción total de la actividad, sino una reducción de la misma, según se deduce del art. 11.2.a) LETA. Con todo, al no estar tipificados como causas justificadas de interrupción, siquiera parcial, de la

\footnotetext{
${ }^{61}$ Precisamente, algún autor había defendido la posibilidad de sustitución del autónomo dependiente en estos casos, como mecanismo para reducir los perjuicios al cliente, y evitar con ello la facultad resolutoria prevista en el art. 16.3 LETA. Así, De Heredia Ruiz, I.B. (2008). La extinción del contrato del autónomo dependiente. Análisis (crítico) de su regulación jurídica (y propuestas de reforma). Aranzadi Social. núm. 4. BIB 2008|859. cit., p. 17.
} 
actividad, sino de reducción de la actividad, cabe cuestionarse si, en estos supuestos, podría considerarse válida la resolución por voluntad del cliente, cuando dicha reducción ocasione un perjuicio importante al cliente que paralice o perturbe el normal desarrollo de su actividad.

Planteada la cuestión en el plano de la legalidad ordinaria, una interpretación sensu contrario del art. 16.1, entendido como una lista cerrada de supuestos excluyentes de la facultad extintiva recogida en el art. 15.1.f) LETA, parece avalar tal posibilidad, sin que el trabajador pueda invocar una vulneración de su derecho profesional a la conciliación de su actividad profesional con la vida personal y familiar, pues el art. 4.3.9) LETA conecta el derecho a la conciliación con la facultad de suspender su actividad por determinadas causas (maternidad, paternidad, adopción o acogimiento y riesgo durante el embarazo y la lactancia), entre las que no cita los supuestos de cuidado de hijo menor de 7 años, ni de familiar dependiente o con discapacidad a su cargo.

Por lo demás, el referido art. 4.3.g) tampoco configura el derecho del autónomo a reducir la actividad por tales causas, como parte del contenido del derecho a la conciliación de la vida familiar y profesional. Señalado lo anterior, no cabe ignorar que, cuando se produzca la reducción o interrupción parcial de la actividad del TRADE por tales causas, el daño derivado para el cliente debería ser menor que en los supuestos de interrupción total que el art. 16 considera justificado, o incluso nulo, cuando se haya cubierto la jornada mediante un contrato de interinidad, de forma que difícilmente podría justificar el despido por tal causa.

Cuestión distinta es que el cuidado de una persona a cargo (menor o familiar dependiente o con discapacidad) requiriera la interrupción de la actividad durante toda la jornada. El art. 16.2 LETA permite que mediante contrato o acuerdo de interés profesional se contemplen estos y otros supuestos entre las causas de interrupción justificadas de la actividad profesional, excluyendo, en su caso, la posibilidad de extinción del contrato si ocasionan un perjuicio importante al cliente que paralice $o$ perturbe el normal desarrollo de su actividad ${ }^{62}$. No obstante, aun en defecto de tales previsiones, cabe defender una aplicación analógica de las previsiones del art. 16.1 y 3 al resto de causas de interrupción por motivos de conciliación en aplicación directa de la prohibición de trato discriminatorio.

En fin, como se ha advertido anteriormente, el art. 16 proporciona una solución parcial al conflicto que se plantea entre los derechos de conciliación y los intereses de la empresa cliente, y no solamente porque las causas de interrupción justificadas no contemplan todos los supuestos de interrupción de la actividad laboral por motivos de conciliación, sino porque en la letra del precepto quedan sin proteger frente a la facultad resolutoria del cliente aquellos casos de interrupción que ocasionan un grave

\footnotetext{
62 Castro Argüelles, M.A. (2011). Los acuerdos de interés profesional: un balance de la negociación llevada a cabo al amparo del Estatuto del trabajo autónomo. Anales de Derecho. Núm. 29. p. 61. 
perjuicio al cliente cuando el autónomo dependiente no opta por contratar a un trabajador sustituto.

Sin embargo, a nuestro juicio, no es posible afirmar, sin más, la validez de la extinción del contrato por parte del cliente, cuando la interrupción de la actividad por parte del autónomo dependiente no se debe a una de las causas de interrupción justificadas o, aun siéndolo, cuando no ha procedido a la contratación de un trabajador sustituto. Aun en estos supuestos, el autónomo dependiente podría impugnar la resolución del contrato por parte del cliente alegando, si es el caso, que la decisión constituye un trato discriminatorio desfavorable por razón de sexo o del ejercicio de sus derechos a la seguridad y salud o de conciliación, en el sentido anteriormente expuesto.

Si el autónomo dependiente impugnara la extinción del contrato invocando motivos discriminatorios, habría que estar a las reglas sobre carga de la prueba y consecuencias de la decisión extintiva previstas en la LRJS, siendo de aplicación la modalidad procesal prevista en los arts. 177 y siguientes para la tutela de los derechos fundamentales $^{63}$, según lo dispuesto en el art. 102.3 LRJS $^{64}$. En consecuencia, si bien no resulta de aplicación el mecanismo de la nulidad objetiva, reservado para los despidos objetivos y disciplinarios [art. 108.2, aptdos. a), b) y c), y art. 122.2, aptdos. c), d) y e) LRJS], sí sería posible declarar la nulidad de la decisión extintiva si, una vez constatada la existencia de indicios suficientes de la causa discriminatoria, la empresa cliente no procediera a "la aportación de una justificación objetiva y razonable, suficientemente probada, de las medidas adoptadas y de su proporcionalidad" (art. 181.2 LRJS) ${ }^{65}$. Llegado el caso, en aplicación de la doctrina constitucional sobre el test de razonabilidad, el cliente debería probar que los hechos motivadores de la decisión son legítimos y se presentan razonablemente ajenos a todo móvil atentatorio del derecho fundamental alegado ${ }^{66}$.

\footnotetext{
63 Navarro Nieto, F. (2012). Especialidades del régimen profesional del TRADE en jornada, interrupciones y extinción de la relación contractual. cit. p. 59.

${ }^{64}$ En línea con lo planteado, en su día, por Barrios Baudor, G.L. (2011). La conciliación de la vida personal, familiar y profesional de los trabajadores autónomos: estado de la cuestión y propuestas de reforma. cit. p. 95 .

${ }^{65}$ Según De Heredia Ruiz, I.B. (2008). La extinción del contrato del autónomo dependiente. Análisis (crítico) de su regulación jurídica (y propuestas de reforma). Aranzadi Social. núm. 4. BIB 2008|859, cit., p.17, no bastaría con justificar la concurrencia del daño o perjuicio importante que perturbe la actividad empresarial del cliente, alegada invocando los arts. 15.1.f) y 16.3 in fine.

${ }^{66}$ Es doctrina reiterada por las SSTC 14/2002, de 28 de enero, 29/2002, de 11 de febrero, 41 y 48/2002, de 25 de febrero, 84/2002, de 22 de abril, 66/2002, de 21 de marzo, 17/2003, de 30 de enero, 49/2003, de 17 de marzo, 171/2003, de 29 de septiembre, 188/2004, de 2 de noviembre, 38/2005, de 28 de febrero, 144/2005, de 6 de junio, 171/2005, de 20 de junio, 138/2006, de 8 de mayo, 168/2006, de 5 de junio, 342/2006, de 11 de diciembre, etc. Para un estudio de la citada doctrina constitucional, aunque en el ámbito de la relación laboral, véase Fernández López, M.F. (2008). La tutela laboral frente a la discriminación por razón de género. Madrid, España: La Ley, Temas, p. 135.
} 
Aunque parezca una obviedad, merece la pena recordar que todo lo anterior se entiende sin perjuicio de la necesidad de extender la protección por maternidad y responsabilidades familiares prevista para las trabajadoras y trabajadores dependientes a quienes, pese a tener formalmente el estatus de autónomos, trabajan por cuenta y en el ámbito de organización de otro empresario ${ }^{67}$. Así, lo ha advertido el TJUE en Danosa v LKB Lizings $S I A^{68}$. Este caso, remitido por un tribunal de Letonia, se refería a la remoción de una directora por decisión del accionista único, por razón de su embarazo. La sentencia, en esencia, concluye que el término "trabajador" tiene un significado general en toda la UE y, si una relación laboral cumple con los requisitos de esa definición ${ }^{69}$, la categorización formal de la relación según la ley nacional como no laboral, no puede alterar el estatus de la persona en cuestión como trabajador, a los efectos de la legislación de la UE (párrafos 41-42). En virtud de esta doctrina comunitaria, merecerían la protección frente a la extinción de su relación de servicios motivada por la maternidad o las responsabilidades familiares, los transportistas "con vehículos comerciales de servicio público cuya propiedad o poder directo de disposición ostenten", excluidos ex lege del ámbito de laboralidad, en virtud el art. 1.3.g), párrafo 2 del ET, cuando dichos servicios se realicen de forma subordinada y por cuenta de un cargador o comercializador.

\section{Conclusiones}

Un buen número de textos normativos y documentos en materia de estrategia de fomento del autoempleo recuerda la necesidad de remover los obstáculos de todo tipo a la iniciativa empresarial, recomendando, además de los tradicionales incentivos económicos que facilitan la puesta en marcha de la actividad y su sostenimiento en la etapa inicial, el aligeramiento de cargas o la supresión de trabas administrativas y mercantiles, y, en particular, la introducción de medidas de apoyo a la conciliación de la vida profesional y familiar. Aunque sus destinatarios son los autónomos de ambos sexos, la introducción de fórmulas para favorecer la conciliación constituye un mecanismo de fomento del emprendimiento femenino, en la medida en que la mujer continúa dedicando más tiempo que el varón a la atención de los menores y las personas dependientes.

Dado que la escasa presencia de las mujeres en el ámbito del autoempleo ha motivado su inclusión expresa entre los colectivos prioritarios para las políticas activas de empleo a instancia de las instituciones comunitarias, parece más que justificada la

\footnotetext{
${ }^{67}$ Napier QC, B. (2017). Division J Family Matters/1. Introduction/C. Self-employed workers. En Napier OC, B., Smith, I.S., Eady OC, J. y McMullen, J. y Brennan, T. Harvey on Industrial Relations and Employment Law. Reino Unido: Lexis Nexis. Paraf. [18].

${ }^{68}$ STJUE de 11 de noviembre de 2010 (C-232/09).

${ }^{69}$ A tenor de la referida STJUE, "la característica esencial de una relación laboral es que, durante un cierto período de tiempo, una persona realiza servicios para y bajo la dirección de otra persona, a cambio de lo cual recibe una remuneración" (párrafo 39).
} 
adopción de medidas adicionales para incrementar el acceso de la mujer al autoempleo. Es, por ello, llamativa la falta de programas específicos de beneficios en las cotizaciones a la Seguridad Social para las trabajadoras autónomas, al margen de las situaciones de maternidad y responsabilidades familiares.

Respecto de los beneficios a la cotización introducidos con el propósito de apoyar a los trabajadores autónomos con responsabilidades familiares, parece criticable la condición de que estos no tengan a trabajadores a su cargo en la fecha de la contratación que justifica el acceso a la bonificación en la cotización establecida en el art. 30 LETA. Sin embargo, es preciso valorar positivamente la ampliación efectuada por la Ley 9/2017, de la edad (de 9 a 12 años) de los menores cuyo cuidado motiva el derecho a la bonificación en las cuotas de los trabajadores y trabajadoras por cuenta propia.

También merece buena acogida la reforma del art. 38 LETA en cuanto suprime el requisito de contratación a un trabajador o trabajadora por cuenta ajena como condición para el disfrute de la bonificación en los supuestos de maternidad, paternidad riesgo durante el embarazo y la lactancia natural, etc., con lo que se facilita el acceso a dicho beneficio en la cotización $y$, de paso, se superan las dificultades interpretativas que planteaba la ausencia de referencia expresa a la contratación de trabajadores sustitutos a tiempo parcial en la anterior regulación del art. 38 LETA. Igualmente, es loable la nueva bonificación recogida en el art. 38 bis LETA, introducida por la Ley 6/2017, para facilitar la reincorporación tras las bajas debidas a maternidad, adopción, guarda con fines de adopción, acogimiento y tutela, si bien cabe invocar una medida en análogo sentido para las trabajadoras por cuenta ajena.

Por otra parte, la necesidad de fomentar el autoempleo, unida a la consideración de que existen ciertas categorías de trabajadores autónomos precisadas de mayor protección (fundamentalmente, los TRADE), ha llevado al legislador a reconocerles ciertos derechos de conciliación que, junto a las correspondientes garantías para su ejercicio, contribuirán al mantenimiento de la actividad profesional por parte de las personas con responsabilidades familiares, en particular, de las trabajadoras autónomas.

No obstante, se observa que las previsiones sobre la jornada y descansos (art. 14 LETA), son escasas y adolecen de una gran imprecisión, de ahí el importante papel que en su concreción pueden jugar los acuerdos de interés profesional. Igualmente conviene recordar la posibilidad de introducir en la contratación pública determinadas cláusulas sociales (arts. 145 y 202 LCSP), encaminadas a fomentar la conciliación de la vida laboral y familiar en todas las fases de la ejecución de los contratos con la Administración Pública, lo que incluye a los autónomos y autónomas eventualmente subcontratados para la prestación de los servicios u obras licitados.

Entre las medidas destinadas a garantizar el ejercicio de los derechos de conciliación por parte del TRADE, cabe destacar la posibilidad de contratación de un trabajador por cuenta ajena durante los descansos por maternidad, paternidad, 
adopción o acogimiento y las situaciones de cuidado de menor de 7 años o de un familiar a cargo [art. 11.2.a) LETA]. Esta previsión comporta la excepción a uno de los requisitos que en el Derecho español diferencian al TRADE del autónomo común, y lleva a considerar la conveniencia de poner el acento más en la nota de la dependencia económica (que también puede darse en el autónomo titular de una microempresa), que en esta exigencia que tampoco constituye la regla general en los países de nuestro entorno.

La posibilidad de contratar a un trabajador interino para atender la prestación comprometida con el cliente, minimiza las posibilidades de incumplimiento $y$, con ello, impide el ejercicio de la facultad resolutoria del contrato con el autónomo dependiente. Por eso, quizá sea una obviedad la precisión que impide al cliente extinguir el contrato cuando el autónomo dependiente haya contratado a un trabajador en los supuestos señalados en el art. 16.3 in fine LETA. No obstante, no está de más la precisión legal, pues blinda al TRADE en el caso de que el empresario cliente alegue un perjuicio grave.

Una interpretación literal sensu contrario de la norma podría dar lugar a la desprotección de los autónomos dependientes que han suspendido o reducido su actividad por cuidado de hijo o de familiar a cargo (supuestos no excluidos expresamente de la facultad resolutoria), o por cualquiera de las causas justificadas de interrupción por motivos de conciliación cuando el autónomo dependiente opte no contratar a un sustituto. En estos supuestos, pese a lo que parece inferirse del art. 16 LETA, su interpretación a la luz de los arts. 14 y 39 CE debería conducir a la interdicción del ejercicio de la facultad resolutoria basado precisamente en la interrupción de la actividad motivada por circunstancias relacionadas con la atención de responsabilidades familiares $y$, muy especialmente, con la maternidad y el riesgo durante el embarazo y la lactancia natural.

En fin, el análisis de las medidas en materia de conciliación que contiene la LETA refleja, no solamente la parquedad, vaguedad e imperfección técnica de alguna de las medidas contempladas, sino también su reducido ámbito subjetivo, pues en su mayoría se limitan al TRADE. Procede, por ello, una reforma normativa que concrete dicha regulación, mejore su contenido tomando, en la medida de lo posible, como modelo los derechos de quienes trabajan por cuenta ajena, y extienda su ámbito de aplicación a los autónomos comunes, en particular, las garantías frente a la extinción del contrato por parte de la empresa cliente, en aquellos casos en que la causa sea la suspensión de la actividad por motivo de la maternidad o de la atención de las responsabilidades familiares del trabajador o la trabajadora autónoma.

\section{Bibliografía}

Agut García, C. y Núñez González, C. (2012). The Regulation of Economically Dependent Self-employed Work in Spain: A Critical Analysis and a Comparison 
with Italy. E-Journal of International and Comparative Labour Studies, Vol.1, Núm. 1-2, pp. 117- 133. Recuperado de http://ejcls.adapt.it/index.php/ejcls_adapt/article/view/22/68

Annink, A., Den Dulk, L. y Steijn, B. (2016). Work-Family conflict among employees and the self-employed across Europe. Social Indicators Research. Vol. 126. pp. 571-593. Disponible en https://link.springer.com/article/10.1007/s11205-0150899-4

Antonmattei, P.H. y Sciberras, J.C. (2008). Le travailleur économiquement dépendant: quelle protection?. Rapport à M. le Ministre du Travail, des Relations sociales, de la Famille et de la Solidarité. Droit Social, núm. 2, pp. 221-233. Recuperado de http://travail-emploi.gouv.fr/IMG/pdf/Rapport-Antonmattei-Sciberraso7NOVo8.pdf

Barrios Baudor, G.L. (2011). La conciliación de la vida personal, familiar y profesional de los trabajadores autónomos: estado de la cuestión y propuestas de reforma. Estudios financieros. Revista de trabajo y seguridad social: Comentarios, casos prácticos: recursos humanos. num. 345. pp. 51-96.

Cabero Morán, E. (2014). Trabajo autónomo e igualdad efectiva de mujeres y hombres: Un nuevo enfoque institucional. En Ramos Quintana, M.I. y Rojas Rivero, G.P. (Coords.). Transformaciones del Estado social y derecho del trabajo: Libro homenaje al profesor Manuel Álvarez de la Rosa, catedrático de Derecho del Trabajo y de la Seguridad Social, con motivo de su jubilación. Granada, España: Comares. pp. 429-442.

Castro Argüelles, M.A. (2011). Los acuerdos de interés profesional: un balance de la negociación llevada a cabo al amparo del Estatuto del trabajo autónomo. Anales de Derecho. Núm. 29. pp. 34-80.

De Heredia Ruiz, I.B. (2008). La extinción del contrato del autónomo dependiente. Análisis (crítico) de su regulación jurídica (y propuestas de reforma). Aranzadi Social. núm. 4. BIB 2008|859.

Fernández López, M.F. (2008). La tutela laboral frente a la discriminación por razón de género. Madrid, España: La Ley, Temas.

Fernández-Costales Muñiz, J. y Álvarez Cuesta, H. (2009). Régimen profesional, derechos colectivos y Seguridad Social del trabajador autónomo tras la Ley 20/2007, de 11 de julio, del Estatuto del Trabajo Autónomo. León, Madrid: Eolas.

Ferrando García, F.M., García Romero, M.B. y López Aniorte, M.C. (2013). Reflexiones sobre la aplicación en España de la estrategia europea de empleo. En Cabeza Pereiro, J. y Fernández Prol, F. (Coords.). Políticas de Empleo (pp. 409-427). Cizur Menor, España: Aranzadi.

Fotinopoulou Basurko, O. (2010). Algunos aspectos relativos a la prevención y protección de la maternidad y la lactancia de las trabajadoras autónomas y 
TRADES. Lan Harremanak: Revista de relaciones laborales. núm. 23. pp. 245275.

Galiana Moreno, J.M. y Selma Penalva, A. (2009). El trabajo autónomo dependiente dos años después de la aprobación del Estatuto del trabajo autónomo. Aportaciones prácticas del RD 197/2009 que desarrolla la Ley 20/2007. Revista del Ministerio de Trabajo e Inmigración. núm. 83. pp. 291-322.

Napier OC, B. (2017). Division J Family Matters/1. Introduction/C. Self-employed workers. En Napier OC, B., Smith, I.S., Eady OC, J. y McMullen, J. y Brennan, T. Harvey on Industrial Relations and Employment Law. Reino Unido: Lexis Nexis.

Lopez Aniorte, M.C. y Rodriguez Egio, M.M. (2015). ¿Favorece el emprendimiento femenino el vigente régimen jurídico de la protección por maternidad biológica?. Revista de derecho social. No 70. pp. 75-96.

Luque Parra, M. y Martínez Fons, D. (2007). Régimen profesional del trabajador autónomo económicamente dependiente. En Del Rey Guanter, S. (Dir.). Comentarios al estatuto del trabajo autónomo. Valladolid, España: Lex nova.

Montoya Melgar, A. (2009). El contrato del TRADE. Madrid, España: Civitas.

Moreno De Vega y Lomo, F. (2008). El trabajador autónomo: la conciliación entre la actividad profesional y su vida familiar. Revista de Derecho Social. núm. 43. pp. 89-104.

Morgado Panadero, P. (2011). Hacia un derecho de ciudadanía sin límites para el trabajador autónomo: el reconocimiento de su vida personal, familiar y profesional. En Morgado Panadero, P. (Coord.). Trabajo autónomo e igualdad: reflexiones desde el Derecho del Trabajo (pp. 93-117). Cizur Menor, España: Aranzadi.

Navarro Nieto, F. (2012). Especialidades del régimen profesional del TRADE en jornada, interrupciones y extinción de la relación contractual, Temas Laborales. núm. 114. pp. 31-59.

OCDE (2011). Doing better for families. Chapter 1: Families are changing. http://www.oecd.org/els/soc/47701118.pdf.

Oreste Cagnasso, O. y Vallebona A. (2014). Dell'impresa e del lavoro, artt. 2188-2246. En Gabrielli, E. (Dir.). Commentario del Codice Civile. Volumen 4. Nota 804. Italia: Utet Giuridica.

Ortiz Garcia, P. y Olaz Capitán, A. (2016). Elements that contribute to boost female entrepreneurship: A prospective analysis. Suma de Negocios. Volume 7. Issue 15. pp. 54-60. Recuperado de https://papers.ssrn.com/sol3/papers.cfm?abstract_id=3013282

Panizo Robles, J.A. (2014). Un paso más en la cobertura económica de la maternidad: la excedencia por cuidado de hijo es compatible con el alta en el Régimen de Autónomos: STS de 10 de febrero de 2015. Aranzadi digital. num.1, parte Estudios y comentarios. BIB 2015|1341. 
Pérez Agulla, S. y Gil Plana, J. (2015). Los trabajadores autónomos y la conciliación de la vida familiar, personal y profesional. En Mella Méndez. L. (Dir.). Conciliación de la vida laboral y familiar y crisis económica. Estudios desde el Derecho Internacional y Comparado (pp. 79-96). España: Editorial DELTA.

Perulli, A. (2003). Travail économiquement dépendant/parasubordination: les aspects juridiques, sociales et économiques. Recuperado de http://www.metiseurope.eu/content/pdf/n8/7_parasubordination.pdf.

Rodríguez Egío, M.M. (2016). Hacia un trabajo autonómo decente. Albacete, España: Bomarzo.

Selma Penalva, A. (2016). Incentivos a la mujer emprendedora. Especial referencia a las recientes reformas introducidas por la Ley 31/2015 de fomento del trabajo autónomo y de la Economía Social. RTSS-CEF. núm. 394. pp. 63-90.

Tremblay, D.-G., Chevrier C. y Di Loreto, M. (2007). Self-Employment: A better reconciliation of personal and professional life ... or more crossover in social times?. Research Note of the Bell Canada Research Chair on Technology and Work Organization, Télé-université, UQAM. Núm. 07. Recuperado de https://www.teluq.uquebec.ca/chairebell/pdf/NR_CB_2007_07.pdf

Rausei, P. (2017). Lavoro autonomo e agile. IPSOA Guide Operative. Milanofiori Assago, Italia: Wolters Kluwer.

Cómo referenciar este artículo/How to reference this article:

Ferrando García, F.M. (2018). Igualdad y conciliación de la vida familiar y la actividad profesional de los trabajadores y trabajadoras autónomas: avances normativos y cuestiones pendientes. iQUAL. Revista de Género e Igualdad, 1, 32-61, doi: 10.6018/iQual.312871

Ferrando García, F.M. (2018). Igualdad y conciliación de la vida familiar y la actividad profesional de los trabajadores y trabajadoras autónomas: avances normativos y cuestiones pendientes. [Equality and reconciliation of family life and autonomous activity of autonomous workers: normative advancements and pending issue]. iQUAL. Revista de Género e Igualdad, 1, 32-61, doi: 10.6018/iQual.312871 